\title{
The earliest results of comprehensive treatment of patients with chronic generalized parodontitis with the predominance of the parasympathetic nervous system
}

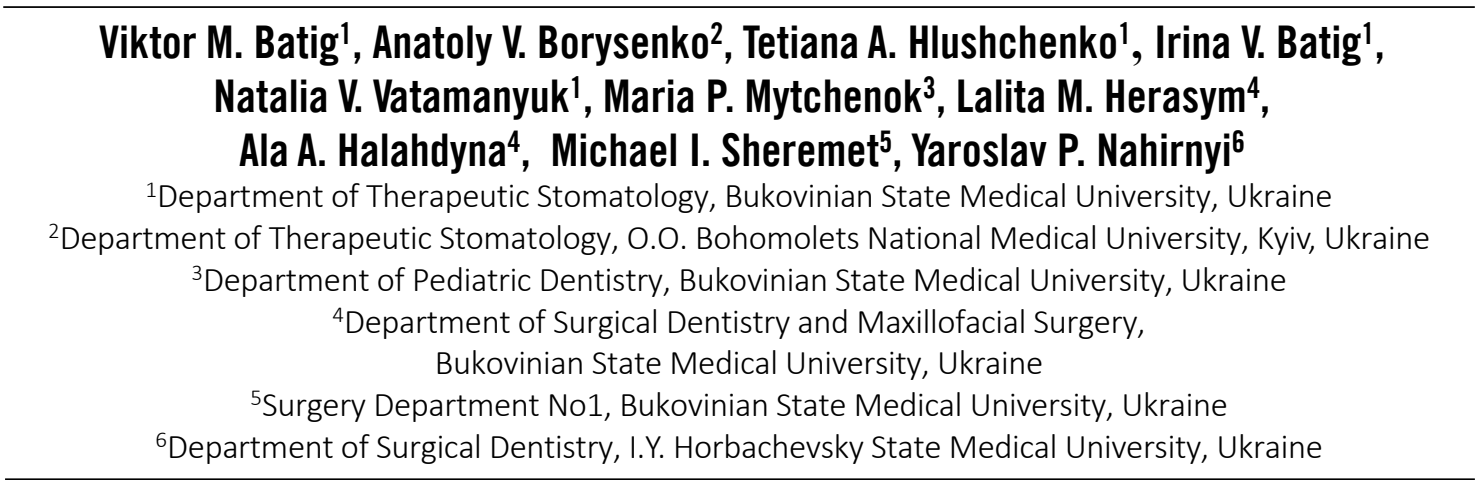

\begin{abstract}
Introduction. In clinical Ukrainian and foreign research papers there are many publications dealing with the treatment of patients suffering from generalized periodontitis. However, there remain a number of issues which have not been covered, including the influence of the autonomic nervous system on the development, course and treatment of periodontal diseases.

The aim of the study. Increase the effectiveness of treatment for patients with chronic generalized periodontitis with the predominance of the parasympathetic nervous system.

Materials and methods. A comprehensive examination of the periodontal tissue condition involved 60 patients. The proposed scheme of medical therapy was applied to the patients in the main group for the comprehensive treatment. The patients from the comparison group were treated similarly to the patients in the main treatment group, but without premedication drugs.

Results. It was found that the application of the proposed premedication in the comprehensive therapy of patients with generalized periodontitis can effectively suppress the degenerative-inflammatory process in periodontal tissues. It is confirmed by the PMA index decreasing, increasing the time of the hematoma formation during the vacuum test by Kulazhenko, and by improving the level of the oral hygiene.

Conclusions. The proposed treatment technique allows eliminating the manifestations of inflammation and achieving stabilization of the dystrophic-inflammatory process in the periodontium in shorter periods. In the nearest terms of observation, earlier and expressed normalization of clinical and laboratory parameters, that characterize the dystrophic-inflammatory process in periodontal disease, is noted.
\end{abstract}

Keywords: generalized periodontitis, parasympathetic nervous system

\section{INTRODUCTION}

It is common to treat patients with generalized periodontitis depending on the features of its course and its clinical picture. Due to this fact, it is necessary to pay attention to the general condition of the patient's body during the treatment. Some general diseases have a significant effect on the clinical picture of generalized periodontitis.
The general condition of the patient's body determines certain features of the clinical course of generalized periodontitis in patients, in particular, its acute course (1-5). The peculiarities of the clinical course of many diseases depend on the state of the patient's autonomic system, including the prevalence of the sympathetic or parasympathetic autonomic nervous system (6-9). This is especially important in the case of an acute course of generalized 
periodontitis, as in this case there is a sharp decrease in overall resistance in patients (10-13).

Thus, the combination of dystrophic-inflammatory periodontal diseases with various general ones occupies a special place in its onset and development $(1,5,8)$. Without taking these features into account, the periodontal diseases have an adverse course and resistance to treatment (14-16). Considering a close relationship between the vascular and nervous systems of periodontium, the autonomic nervous system plays an integrative role $(3,6,9,11)$.

In recent years, interest has increased in the study of the peculiarities of the influence of the autonomic nervous system on the development of generalized periodontitis $(1,5,8,15)$. Certain features of the course of various pathological conditions depending on the state of the autonomic nervous system have been noted and they should be considered in its treatment $(7,11,15)$. Due to this fact, a medical treatment scheme for generalized periodontitis was proposed in patients with predominance of parasympathetic autonomic nervous system $(4,7,9)$. Treatment of patients with generalized periodontitis should be carried out in a comprehensive manner, depending on the peculiarities of its course and the clinical picture of the disease (17-20). In doing so, the general condition of the patient's body must be taken into account, which has a significant impact on the course of the disease and the outcome of treatment $(6,8,16)$. The development of periodontal diseases is quite often determined by the patient's common diseases of various organs and systems $(11,17,19)$. In addition, one should take into account the impact of the state of the autonomic nervous system on the development of these diseases and, in the future, on generalized periodontitis (20-24). Depending on the state of the autonomic nervous system, the course of these common diseases is different, which should be taken into account during the treatment of generalized periodontitis $(1,6,17,23)$.

Therefore, studying the state of the autonomic nervous system in patients with generalized periodontitis is of great importance for the development of the most effective methods of treating periodontal diseases in them. The integrative role of the autonomic nervous system on the vascular and nervous systems of periodontal tissues should also be considered. Achieving the balance of sympathet- ic-parasympathetic relationships can improve the blood flow.

\section{OBJECTIVE}

Increase the effectiveness of treatment for patients with chronic generalized periodontitis with the predominance of the parasympathetic nervous system.

\section{MATERIALS AND METHODS}

Clinical studies involved 60 patients with chronic generalized periodontitis who were divided into two groups - the main and the comparison ones.

A comprehensive examination of the condition of periodontal tissues in patients before and after the treatment was performed. To evaluate the clinical efficacy of the treatment, the Schiller-Pisarev test (1), C. Parma PMA index (3), the FedorovVolodkin's hygiene index (1), and the Kulazhenko vacuum test (3) were used.

The main group consisted of 40 (66.67\%) patients with generalized periodontitis, who were administered a scheme of medical therapy in their comprehensive treatment, which includes a two day course of Buscopan $0.01 \mathrm{~g}-1$ tablet 3 times a day and tincture of valerianum in 25 drops 3 times a day before each visit to the dentist, as well as after the stomatological intervention a 3 day course of: Ibuprofen $0.2 \mathrm{~g}-2$ tablets 3 times a day, tincture of valerianum 20 drops 3 times a day and Buskopan $0.01 \mathrm{~g}-1$ tablet 3 times a day.

The comparison group consisted of 20 (33.33\%) patients with generalized periodontitis, whose comprehensive treatment was similar to the patients in the main treatment group, but without using premedication drugs.

\section{RESULTS}

Patients with generalized periodontitis were divided into two groups before the clinical examination - the main and the comparison group according to the degree and course of the disease (Table 1).

As a result, the main group consisted of 40 (66.67\%) patients with generalized periodontitis, who were administered a proposed scheme of medical therapy in their comprehensive treatment. 
TABLE 1. Distribution of patients with generalized periodontitis with the predominance of the parasympathetic nervous system in the main and comparison groups

\begin{tabular}{|c|c|c|c|c|c|c|c|c|}
\hline \multirow{3}{*}{ Experimental groups } & \multicolumn{4}{|c|}{ Degree of generalized periodontitis } & \multicolumn{2}{|c|}{$\operatorname{sex}$} & \multirow{2}{*}{\multicolumn{2}{|c|}{ Total number of patients }} \\
\hline & \multicolumn{2}{|c|}{ I degree } & \multicolumn{2}{|c|}{ Il degree } & \multirow[t]{2}{*}{ male } & \multirow[t]{2}{*}{ female } & & \\
\hline & abs. & $\%$ & abs. & $\%$ & & & abs. & $\%$ \\
\hline Main group & 24 & 40.00 & 16 & 26.67 & 11 & 29 & 40 & 66.67 \\
\hline Comparison group & 11 & 18.33 & 9 & 15.00 & 6 & 14 & 20 & 33.33 \\
\hline Total & 35 & 58.33 & 25 & 41.67 & 17 & 43 & 60 & 100 \\
\hline
\end{tabular}

The comparison group consisted of $20(33.33 \%)$ patients with generalized periodontitis, whose comprehensive treatment was similar to the patients in the main treatment group, but without using premedication drugs.

The course of treatment for patients with the first degree generalized periodontitis in the main group was on average 6.05 visits, in the comparison group - 9.18 visits. To achieve stabilization of the pathological process in the patients with the second-degree generalized periodontitis it was necessary 8.46 visits for the patients in the main group and 10.2 visits for the patients in the comparison group (Table 2).

TABLE 2. The number of patient visits required to achieve the stabilization of the dystrophic-inflammatory process $(M \pm m)$

\begin{tabular}{|l|c|c|}
\hline \multirow{2}{*}{ Experimental groups } & \multicolumn{2}{|c|}{ Number of visits } \\
\cline { 2 - 3 } & $\begin{array}{c}\text { I degree } \\
(\mathrm{n}=35)\end{array}$ & $\begin{array}{c}\text { II degree } \\
(\mathrm{n}=25)\end{array}$ \\
\hline Main group $(\mathrm{n}=40)$ & $6.05 \pm 0.25$ & $8.46 \pm 0.18$ \\
\hline $\begin{array}{l}\text { Comparison group } \\
(\mathrm{n}=20)\end{array}$ & $9.18 \pm 0.32^{*}$ & $10.2 \pm 0.25^{*}$ \\
\hline
\end{tabular}

*the figures are reliably different from those in the main group

After the comprehensive treatment, the patients in both groups experienced improvement in general well-being, the disappearance of unpleasant sensations and mouth odor, of gum pain and bleeding. Objectively, the mucous membrane of the gum acquired a pale pink color, it was densified and firmly covered the hard tissues of the tooth.

The comprehensive treatment led to a significant improvement in the hygienic status of the patients with generalized periodontitis. This is evidenced by the positive dynamics of the OHI-S index of hygiene.

In patients with the $1^{\text {st }}$ degree generalized periodontitis of the main group, the OHI-S index of hygiene decreased from $1.45 \pm 0.09$ to $0.57 \pm 0.05$ points; in patients with the second degree of the disease the index decreased from $1.85 \pm 0.05$ to $0.75 \pm 0.04$ points. In general, in the patients of the main group, the index of OHI-S decreased by $50.31 \%$ from $1.59 \pm 0.09$ to $0.79 \pm 0.06$ points, which corresponds to the level of good oral hygiene.

In patients with the first degree generalized periodontitis in the comparison group, the OHI-S index of hygiene decreased from $1.44 \pm 0.09$ to $0.85 \pm 0.06$ points; in patients with second degree of the disease the index decreased from $1.91 \pm 0.06$ to $0.75 \pm 0.04$ points. In general, the value of the index of hygiene decreased by $41.90 \%$ from $1.48 \pm$ 0.08 to $0.86 \pm 0.06$ points in the patients from the group of comparisons, which also corresponds to the level of good oral hygiene. The obtained values of the indexes of hygiene in patients of the main group and the comparison group did not differ statistically reliably ( $p>0.05)$ from each other.

The examination did not find pathological mobility of the lower frontal teeth. In the patients of the main group, Schiller-Pisarev's test was negative in 20 out of $24(83.33 \%)$ persons with the first degree generalized periodontitis and in 12 of 16 $(75.00 \%)$ thoses with the second degree generalized periodontitis. In total, the Schiller-Pisarev's test was negative in $33(82.5 \%)$ patients in the main group of patients with generalized periodontitis. In the comparison group, the Schiller-Pisarev test was negative in 7 out of $11(63.63 \%)$ patients with the first degree generalized periodontitis and 5 out of 9 (55.56\%) those with the second degree generalized periodontitis. In total, the Schiller-Pisarev's test was negative in $33(82.5 \%)$ patients in the main group of patients with generalized periodontitis. In total, the Schiller-Pisarev's test was negative in 13 (65.0\%) patients in the comparison group of patients with generalized periodontitis. The quantitative value of the Schiller-Pisarev test by the iodine 
number of Svrakov was $2.6 \pm 0.25$ in patients with generalized periodontitis of the main group prior to the treatment and $1.4 \pm 0.15(\mathrm{p}<0.05)$ after the treatment. In the comparison group, it was equal to $2.7 \pm 0.25$ and $1.9 \pm 0.18(\mathrm{p}<0.05)$ respectively. The obtained data differ statistically reliably ( $p$ $<0.05$ ) from those in the main group.

Reducing gum inflammation was confirmed by the value of the PMA index. In patients from the main group with the first degree of the disease its value decreased from $60.9 \pm 2,1 \%$ to $8.3 \pm 0.88 \%$, and in patients with the second degree it decreased from $67.3 \pm 2.7 \%$ to $11.3 \pm 0.85 \%$. On average, the PMA index fell from $64.15 \pm 2.45$ and was $8.6 \pm$ $0.78 \%$ in the main group after the treatment. There was a significant reduction in gum inflammation in the comparison group as well: the PMA index decreased from $65.35 \pm 3.51 \%$ to $12.8 \pm 0.98 \%$, the figure is reliably different statistically $(\mathrm{p}<0.05)$ from the data in the main group. In particular, in patients from a comparison group with the first degree of the disease its value decreased from $61.5 \pm$ $2.5 \%$ to $11.64 \pm 0.98 \%$, and in patients with the second degree it decreased from $65.35 \pm 3.51 \%$ to $14.96 \pm 1.08 \%$. The findings obtained in patients of the main group and the comparison group were statistically reliably $(\mathrm{p}<0.05)$ different.

Due to the comprehensive treatment, the sulcus bleeding index (SBI) decreased: in patients in the main group it decreased from $2.81 \pm 0.19$ to $0.71 \pm$ 0.02 points and in patients in the comparison group - from $2.38 \pm 0.22$ to $0.89 \pm 0.02$ points. There was a reliable statistical difference $(p<0.05)$ between the SBI in patients of these groups. In particular, in patients with the first degree generalized periodontitis after the treatment, the sulcus bleeding index (SBI) in the main group decreases by 2.74 times ( $p$ $<0.05$ ) from $1.81 \pm 0.19$ to $0.66 \pm 0.02$ points, and in persons from the comparison group - by 2.2 times $(p<0.001)$ from $1.74 \pm 0.22$ to $0.79 \pm 0.02$ points. These figures were somewhat lower in patients with the second degree generalized periodontitis: the rate of SBI decreased by 3.75 times in the main group from $2.85 \pm 0.66$ to $0.76 \pm 0.03$ points and by 2.69 times in the comparison group - from $2.64 \pm 0.36$ to $0.98 \pm 0.03$ points.

Changes in periodontal index (PI) at the stages of treatment indicate the condition of the whole complex of periodontal tissues. In the development of the dystrophic-inflammatory process in the periodontal period, the value of the periodontal index increases dramatically on average to $1.87 \pm 0.48$ points in the first degree generalized periodontitis and to $3.60 \pm 0.50$ points in the second degree generalized periodontitis. After the comprehensive treatment of patients with generalized periodontitis, the value of the index decreases. In patients with the first degree generalized periodontitis in the main group, the PI index decreased by $65.64 \%$ from $1.87 \pm 0.48$ to $0.68 \pm 0.05$ points, in patients with the second degree of the disease it decreased by $77.23 \%$ from $3.60 \pm 0.50$ to $0.82 \pm 0.08$ points. In general, in patients of this main group, the PI index decreased by $68.3 \%$ from $2.49 \pm 0.3$ to 0.71 \pm 0.07 points.

After the treatment the periodontal index in the comparison group decreased in patients with the first-degree generalized periodontitis from $1.82 \pm$ 0.64 to $0.51 \pm 0.01$ points and in patients with the second-degree generalized periodontitis it decreased from $3.72 \pm 0.41$ to $0.91 \pm 0.06$ points. On average, in patients from the comparison group, the periodontal index decreased by $6.78 \%$ from $2.52 \pm$ 0.48 to $0.89 \pm 0.07$ points. The periodontal indices in patients of these clinical groups were reliably statistically $(\mathrm{p}<0.05)$ different (Table 3$)$.

Therefore, the state of hygiene of the oral cavity improved after a course of treatment: the index of hygiene OHI-S in patients from the main group decreased on average from $1.59 \pm 0.09$ to $0.79 \pm 0.06$. The level of inflammation of the gums decreased as evidenced by the PMA index - it was on average $8.6 \pm 0.78 \%$ after the treatment.

The strength of the peripheral vessels of the gums, which was determined by a vacuum test of V.I. Kulazhenko, increased. In the chronic course before the treatment of generalized periodontitis, vacuum hematoma was formed on average after $11.3+1.5$ seconds. After the treatment, the time of formation of vacuum hematoma increased to $24.7 \pm$ 2.7 seconds, which indicates an increase in the resistance of the gum capillaries.

Depending on the nature and severity of the dystrophic-inflammatory process in the periodontal tissues, the number of leukocytes migrating into the oral cavity increases. Their quantity is largely determined by the state of the gum capillary permeability and the nature of the course of generalized 
TABLE 3. Values of periodontal tissue condition in patients with generalized periodontitis with predominance of parasympathetic vegetative nervous system in the earliest terms of observation $(M \pm m)$

\begin{tabular}{|c|c|c|c|c|c|}
\hline \multirow{3}{*}{ Values } & \multirow{3}{*}{ Terms of examination } & \multicolumn{2}{|c|}{ I degree } & \multicolumn{2}{|c|}{ II degree } \\
\hline & & \multicolumn{4}{|c|}{ Experimental groups } \\
\hline & & Main & Comparison & Main & Comparison \\
\hline \multirow[t]{2}{*}{ OHI-S (points) } & Before treatment & $1.45 \pm 0.09$ & $1.48 \pm 0.08$ & $1.85 \pm 0.05$ & $1.91 \pm 0.06$ \\
\hline & After treatment & $0.57 \pm 0.05^{*}$ & $0.86 \pm 0.06$ & $0.85 \pm 0.06$ & $0.75 \pm 0.04$ \\
\hline \multirow{2}{*}{$\begin{array}{l}\text { The Schiller-Pisarev test } \\
\text { (points) }\end{array}$} & Before treatment & $2.6 \pm 0.25$ & $2.7 \pm 0.25$ & $2.9 \pm 0.25$ & $2.8 \pm 0.25$ \\
\hline & After treatment & $1.4 \pm 0.15$ & $1.9 \pm 0.18$ & $1.5 \pm 0.15$ & $2.1 \pm 0.15$ \\
\hline \multirow[t]{2}{*}{ SBI (points) } & Before treatment & $1.81 \pm 0.19$ & $1.74 \pm 0.22$ & $2.85 \pm 0.66$ & $2.64 \pm 0.36$ \\
\hline & After treatment & $0.66 \pm 0.02 *$ & $0.79 \pm 0.02$ & $0.76 \pm 0.03^{*}$ & $0.98 \pm 0.03$ \\
\hline \multirow{2}{*}{$\begin{array}{l}\text { Depth of periodontal } \\
\text { pockets }(\mathrm{mm})\end{array}$} & Before treatment & $2.7 \pm 0.37$ & $2.6 \pm 0.35$ & $3.4 \pm 0.41$ & $3.5 \pm 0,42$ \\
\hline & After treatment & $1.3 \pm 0.25$ & $1.4 \pm 0.25$ & $2.3 \pm 0.25$ & $2.6 \pm 0,25$ \\
\hline \multirow[t]{2}{*}{ PMA (\%) } & Before treatment & $60.9 \pm 2.1$ & $61,5 \pm 2,5$ & $67,3 \pm 2,7$ & $69,2 \pm 3,5$ \\
\hline & After treatment & $8.3 \pm 0.88^{*}$ & $11,64 \pm 0,98$ & $11.3 \pm 0.85^{*}$ & $14.96 \pm 1,08$ \\
\hline \multirow[t]{2}{*}{ PI (points) } & Before treatment & $1.87 \pm 0.48$ & $1.82 \pm 0.64$ & $3.60 \pm 0.50$ & $3.72 \pm 0.41$ \\
\hline & After treatment & $0.68 \pm 0.05 *$ & $0.51 \pm 0.01$ & $0.82 \pm 0.08 *$ & $0.91 \pm 0.06$ \\
\hline
\end{tabular}

note: * the findings are reliably different $(p<0.05)$ from those in the comparison group

periodontitis. In the chronic course of the pathological process in the periodontium, it is equal on average to $388.7 \pm 47.3$ cells in $1 \mathrm{~mm}^{3}$ of lavage fluid. Percentage of live neutrophil granulocytes was on average $64.5 \pm 4.6 \%$. Accordingly, the number of the keratinized epithelium cells increased to $197.6 \pm 8.4$.

After a comprehensive treatment, there is a decrease in the leukocyte emigration into the oral cavity on average to $178.7 \pm 36.8$ cells per $1 \mathrm{~mm}^{3}$ of the lavage fluid. The number of live neutrophilic granulocytes increases to $81.5 \pm 4.3$ in accordance with the nature of the course of generalized periodontitis. The number of the keratinized epithelium cells decreased to $94.4 \pm 7.7$ cells in $1 \mathrm{~mm}^{3}$ of the lavage fluid respectively. Therefore, there is a significant decrease in the number of leukocytes migrating into the oral cavity and cells of the keratinized epithelium, indicating a decrease in the intensity of inflammation in periodontal tissues. In the comparison group these changes are pronounced somewhat less (Table 4).
Studying the content of periodontal pockets found a significant amount of different microflora and a number of various cellular elements. The cells were mainly represented by neutrophilic granulocytes at different stages of necrobiosis. A considerable amount of their destroyed forms is noted - an average of $67.3 \%$. Phagocytosis is detected in a relatively small number of neutrophilic granulocytes. There was often incomplete phagocytosis, indicating the inhibition of protective processes in the periodontal tissues. In a relatively smaller number of periodontal pockets, lymphocytes, polyblasts and epithelial cells were found (Table 5).

After the treatment the number of cellular elements and the amount of microflora are significantly reduced in the periodontal pockets of patients with generalized periodontitis. The relative amount of unchanged neutrophil granulocytes increases and the number of their destroyed forms decreases. At the same time, the amount of phagocytosis increases. As the phenomena of inflammation of the

TABLE 4. Dynamics of leukocyte migration into the oral cavity in the treatment of patients with generalized periodontitis with predominance of parasympathetic vegetative nervous system (of cells in $1 \mathrm{~mm}^{3}$ of lavage fluid)

\begin{tabular}{|c|c|c|c|c|c|c|c|}
\hline $\begin{array}{l}\text { Subgroups of } \\
\text { patients }\end{array}$ & $\begin{array}{l}\text { Time of } \\
\text { examination }\end{array}$ & $\begin{array}{l}\text { Neutrophilic } \\
\text { granulocytes }\end{array}$ & $\mathrm{p}$ & $\begin{array}{l}\text { Including the } \\
\text { live ones } \%\end{array}$ & $p$ & $\begin{array}{l}\text { Cells of the } \\
\text { keratinized } \\
\text { epithelium }\end{array}$ & $p$ \\
\hline \multirow[t]{2}{*}{ Main subgroup } & Before treatment & $388.7 \pm 47.3$ & \multirow{2}{*}{$\begin{array}{l}p 1<0.05 \\
p 2<0.05\end{array}$} & $64.5 \pm 4.6$ & \multirow[t]{2}{*}{$\mathrm{p} 1<0.05$} & $197.6 \pm 8.4$ & \multirow{2}{*}{$\begin{array}{l}\mathrm{p} 1<0.05 \\
\mathrm{p} 2<0.05\end{array}$} \\
\hline & After treatment & $178.7 \pm 36,8$ & & $81.5 \pm 4.3$ & & $94.4 \pm 7.7$ & \\
\hline \multirow{2}{*}{$\begin{array}{l}\text { Comparison } \\
\text { subgroup }\end{array}$} & Before treatment & $374.4 \pm 25.2$ & \multirow[t]{2}{*}{$\mathrm{p} 1<0.05$} & $70.9 \pm 2.8$ & \multirow{2}{*}{$\begin{array}{l}\mathrm{p} 1>0.05 \\
\mathrm{p} 2>0.05\end{array}$} & $196.2 \pm 8.7$ & \multirow[t]{2}{*}{$\mathrm{p} 1<0.05$} \\
\hline & After treatment & $246.7 \pm 12.3$ & & $82.1 \pm 2.6$ & & $108 \pm 8.4$ & \\
\hline
\end{tabular}

Note: $p 1$ - reliability index in the difference between the findings in the main and control groups before and after the treatment; p2 - reliability index in the difference between the findings in the main and comparison groups after the treatment. 
TABLE 5. Dynamics of cytological content of periodontal pockets in the treatment of patients with generalized periodontitis with predominance of parasympathetic autonomic nervous system (\% of diagnosing)

\begin{tabular}{|l|c|c|c|c|c|c|}
\hline \multirow{2}{*}{ Cellular elements } & \multicolumn{3}{|c|}{ Main group } & \multicolumn{3}{c|}{ Comparison group } \\
\cline { 2 - 7 } & Before treatment & After treatment & $\mathrm{p}$ & Before treatment & After treatment & $\mathrm{p}$ \\
\hline Epithelial & $7.25 \pm 0.5$ & $14.21 \pm 0.9$ & $<0.05$ & $4.43 \pm 0.5$ & $6.12 \pm 0.8$ & $<0.05$ \\
\hline $\begin{array}{l}\text { Neutrophilic granulocytes: } \\
\text { unchanged }\end{array}$ & $29.12 \pm 1.37$ & $38.34 \pm 1.3$ & $<0.05$ & $28.45 \pm 1.2$ & $34.23 \pm 1.2$ & $<0.05$ \\
\hline phagocytes & $0.47 \pm 0.12$ & $1.79 \pm 0.27$ & $<0.05$ & $0.45 \pm 0.11$ & $0.96 \pm 0.14$ & $<0.05$ \\
\hline destroyed & $61.43 \pm 2.45$ & $42.32 \pm 2.1$ & $<0.05$ & $61.19 \pm 2.8$ & $54.65 \pm 2.7$ & $<0.05$ \\
\hline lymphocytes & $0.43 \pm 0.15$ & $1.47 \pm 0.21$ & $<0.05$ & $0.52 \pm 0.18$ & $1.15 \pm 0.21$ & $<0.05$ \\
\hline Polyblasts & $0.57 \pm 0.15$ & $1.45 \pm 0.17$ & $<0.05$ & $0.51 \pm 0.15$ & $1.13 \pm 0.15$ & $<0.05$ \\
\hline
\end{tabular}

Note: $p$ - reliability index in the difference between the findings in the main and comparison groups after the treatment

pathological process are eliminated, the number of polyblasts and epithelial cells increases. In the comparison subgroup these changes are expressed to a lesser extent. Compared to the cytological picture of the content of periodontal pockets, a less pronounced decrease in the number of destroyed neutrophil granulocytes, an increase in the amount of phagocytosis is observed after the treatment in the comparison group (Table 5).

Based on the criteria of the effectiveness in the treatment of the dystrophic and inflammatory process in the periodontal disease, the results of treatment for patients with generalized periodontitis have been established (Table 6). In general, after a comprehensive treatment, stabilization of the pathological process was achieved in $36(90.0 \%)$ out of 40 patients in the main group. Of these, 24 $(60.0 \%)$ patients with the first degree generalized periodontitis and $12(30.0 \%)$ patients with the second degree generalized periodontitis. In the comparison group, favorable treatment outcomes were achieved in $14(70.00 \%)$ out of 20 patients in the main group. Of these, $8(40.0 \%)$ out of 11 patients with the first degree generalized periodontitis and 6 $(30.0 \%)$ out of 9 patients with the second degree generalized periodontitis. There was no deteriora- tion of the periodontal state and the therapy in in both groups was effective.

\section{CONCLUSIONS}

Treating patients with generalized periodontitis with a predominance of parasympathetic autonomic nervous system and using the proposed premedication drugs led to a significant improvement in the periodontal condition. The proposed treatment technique allows eliminating the manifestations of inflammation and achieving stabilization of the dystrophic-inflammatory process in the periodontium in shorter periods of treatment. In the nearest terms of observation, earlier and expressed normalization of clinical and laboratory parameters that characterize the dystrophic-inflammatory process in periodontal disease is noted. The obtained data are indicative of an pronounced favorable effect of the proposed premedication in the treatment of patients with generalized periodontitis with the predominance of parasympathetic autonomic nervous system. Therefore, analysing the results of clinical and laboratory research methods immediately after the comprehensive treatment showed a high therapeutic efficacy of various forms and ways of influencing the periodontal with the proposed drugs.

\section{REFERENCES}

1. Kérdö I. EinausDaten der Blutzirkulationkalkulierter Index zurBeurteilung der vegetativenTonuslage. ActaNeurovegetativa. 1966;29(2):250-68.

2. Kinane DF. Causation and pathogenesis of periodontal disease. Periodontol 2000. 2001;25:8-20.

3. Parma C. Parodontopathien. Leipzig: Barth; 1960. 203 p.

4. Sağlam M, Arslan U, BuketBozkurt Ş, Hakki SS. Boric acid irrigation as an adjunct to mechanical periodontal therapy in patients with chronic periodontitis: A randomized clinical trial. J Periodontol. 2013; 84(9):1297-308. doi: 10.1+902/jop.2012.120467

5. da Costa LFNP, Amaral CDSF, Barbirato DDS, Leão ATT, Fogacci MF. Chlorhexidine mouthwash as an adjunct to mechanical therapy in chronic periodontitis: A meta-analysis. J Am Dent Assoc. 2017;148(5):308-18. doi: 10.1016/j.adaj.2017.01.021

6. Assem NZ, Alves MLF, Lopes AB, Gualberto EC Junior, Garcia VG, Theodoro $\mathrm{LH}$. Antibiotic therapy as an adjunct to scaling and root planing in smokers: A systematic review and meta-analysis. Braz Oral Res(Internet). 2017 (cited 2019 Jan 23);31:e67. Available from:http://www.scielo.br/scielo.php?script=sci_arttext\&pid=S1806- 
83242017000100951\&lng=en\&tlng=endoi: 10.1590/1807-3107BOR2017.vol31.0067

7. Rovai ES, Souto ML, Ganhito JA, Holzhausen M, Chambrone L, Pannuti CM.Efficacy of Local Antimicrobials in the Non-Surgical Treatment of Patients With Periodontitis and Diabetes: A Systematic Review. J Periodontol. 2016;87(12):1406-17. doi:10.1902/ jop.2016.160214

8. Xue D, Zhao Y. Clinical effectiveness of adjunctive antimicrobial photodynamic therapy for residual pockets during supportive periodontal therapy: A systematic review and meta-analysis. PhotodiagnosisPhotodynTher. 2017;17:127-33. doi: 10.1016/j. pdpdt.2016.11.011

9. Lang NP, Tan WC, Krähenmann MA, Zwahlen M. A systematic review of the effects of full-mouth debridement with and without antiseptics in patients with chronic periodontitis. J ClinPeriodontol. 2008;35(8 Suppl):8-21. doi: 10.1111/j.1600-051X.2008.01257.x

10. Herrera D, Sanz M, Jepsen S, Needleman I, Roldán S. A systematic review on the effect of systemic antimicrobials as an adjunct to scaling and root planing in periodontitis patients. J ClinPeriodontol. 2002;29(Suppl 3):136-59.

11. Bonito AJ, Lux L, Lohr KN. Impact of local adjuncts to scaling and root planing in periodontal disease therapy: A systematic review. J Periodontol. 2005;76(8):1227-36.doi:10.1902/jop.2005.76.8.1227

12. Gerber FA, Sahrmann P, Schmidlin OA, Heumann C, Beer JH, Schmidlin PR. Influence of obesity on the outcome of non-surgical periodontal therapy - a systematic review. BMC Oral Health (Internet). 2016(cited 2019 Jan 25);16(1):90. Available from:https:// bmcoralhealth.biomedcentral.com/track/pdf/10.1186/s12903-0160272-2doi: 10.1186/s12903-016-0272-2

13. Wambier LM, de Geus JL, Chibinski AC, Wambier DS, Rego RO, Loguercio $A D$, et al. Intra-pocket anaesthesia and pain during probing, scaling and root planing: A systematic review and metaanalysis. J ClinPeriodontol. 2016;43(9):754-66. doi: 10.1111/ jcpe. 12565

14. Matarese G, Ramaglia L, Cicciù M, Cordasco G, Isola G.The Effects of Diode Laser Therapy as an Adjunct to Scaling and Root Planing in the Treatment of Aggressive Periodontitis: A 1-Year Randomized Controlled Clinical Trial. Photomed Laser Surg. 2017;35(12):702-9. doi:10.1089/pho.2017.4288

15. Pamuk F, Lütfioğlu M, Aydoğdu A, Koyuncuoglu CZ, Cifcibasi E, Badur OS. The effect of low-level laser therapy as an adjunct to non-surgical periodontal treatment on gingival crevicular fluid levels of transforming growth factor-beta 1 , tissue plasminogen activator and plasminogen activator inhibitor 1 in smoking and non-smoking chronic periodontitis patients: A split-mouth, randomized control study. J Periodontal Res. 2017;52(5):872-82. doi: 10.1111/jre.12457

16. Soeroso Y, Akase T, Sunarto H, Kemal Y, Salim R, Octavia M et al. The risk reduction of recurrent periodontal pathogens of local application minocycline $\mathrm{HCl} 2 \%$ gel, used as an adjunct to scaling and root planing for chronic periodontitis treatment. TherClin Risk Manag (Internet). 2017(cited 2019 Jan 23);13:307-14. Available from:https://www.dovepress.com/the-risk-reduction-of-recurrentperiodontal-pathogens-of-local-applica-peer-reviewed-fulltext-articleTCRMdoi: 10.2147/TCRM.S130257

17. Mahendra J, Mahendra L, Muthu J, John L, Romanos GE. Clinical effects of subgingivally delivered spirulina gel in chronic periodontitis cases: A placebo controlled clinical trial. J ClinDiagn Res. 2013;7(10):2330-3. doi: 10.7860/JCDR/2013/5793.3517

18. Paolantonio M, Dolci M, Perfetti G, Sammartino G, D'Archivio D, Spoto $G$ et al. Effect of a subgingivalchlorhexidine chip on the clinical parameters and the levels of alkaline phosphatase activity in gingival crevicular fluid during the non-surgical treatment of periodontitis. J BiolRegulHomeost Agents. 2008;22(1):63-72.

19. Greenstein G, Rethman MP. Advantages and limitations of nonsurgical periodontal therapy in the management of chronic periodontitis. Alpha Omegan. 2000;93(4):34-42.

20. Slots J. Periodontitis: Facts, fallacies and the future. Periodontol 2000. 2017;75(1):7-23. doi: 10.1111/prd.12221

21. Sanz M, Teughels W,Adriaens $P$, Armitage G, Baehni P, Chapple I et al. Innovations in non-surgical periodontal therapy: Consensus Report of the Sixth European Workshop on Periodontology. J ClinPeriodontol. 2008;35(8 Suppl):3-7. doi: 10.1111/j.1600-051X.2008.01256.X

22. Finkbeiner RL. The results of 1328 periodontal pockets treated with the argon laser: selective pocket thermolysis. J Clin Laser Med Surg. 1995;13(4):273-81. doi: 10.1089/clm.1995.13.273

23. Gartenmann SJ, Dörig I, Sahrmann P, Held U, Walter C, Schmidlin PR. Influence of different post-interventional maintenance concepts on periodontal outcomes: an evaluation of three systematic reviews. BMC Oral Health (Internet). 2016(cited 2019 Jan 25);17(1):19. Available from: https://bmcoralhealth.biomedcentral.com/ articles/10.1186/s12903-016-0244-6doi: 10.1186/s12903-016-0244-6

24. Gaunt F, Devine M, Pennington M, Vernazza C, Gwynnett E, Steen N et al. The cost-effectiveness of supportive periodontal care for patients with chronic periodontitis. J ClinPeriodontol. 2008;35(8 Suppl):67-82. doi: 10.1111/j.1600-051X.2008.01261.x 